\title{
A STUDY OF TEACHING METHODS USED BY PRE-SERVICE ENGLISH TEACHERS
}

\author{
Nuchanart Nakchaya* \\ English Department, Faculty of Education, Suratthani Rajabhat University, Thailand
}

\begin{abstract}
Pre-service teachers from the English Department, Faculty of Education, Suratthani Rajabhat University were prepared various teaching approaches and methods for their teaching practicum. Each method was possibly used under various considerations and purposes. This research was aimed to investigate the teaching methods used by pre-service teachers while practicing the teaching and also to study about the impacts on learners' learning using those selected methods. The twenty participants were selected by purposive sampling. The observation forms were designed to gather data on teaching behaviors and learners' learning behaviors. The semi-structured interview was used for individual interviews. The findings revealed that three majors of teaching methods including the Grammar Translation Method, Audio-Lingual Method, and Total Physical Response were used by the pre-service teachers. Interestingly, Total Physical Response and Audio-Lingual Method were mostly used in primary schools while the Grammar Translation Method was mostly found in secondary schools. The primary school learners merely learned with enthusiasm to imitate the language while the secondary school learners learned about the forms and structures to pass the exam. Supervising and coaching by supervisors were played an important role. Pre-service teachers should be closely supervised and trained to implement various teaching methods and approaches that including the teaching techniques for their teaching performance in order to maintain the positive impacts on their learners' learning.
\end{abstract}

Keywords: teaching methods, pre-service English teachers, teaching practice, learners' learning impacts

\section{Introduction}

\section{The importance of the study}

English ability for education seems to be a priority issue to be considered since English can be a crucial tool for people to survive in the present. Certainly, Thailand is also one of the countries in the world which has been developing people' English ability for many years. It can be recently and clearly seen when the government by the Office of the Basic Education Commission of Thailand (2016) has announced that English should be used in teaching for at least 200 hours per year in a primary school level (grade1 -3) and also teachers must be trained in how to teach English effectively in order to develop students' English ability for the globalized world.

In terms of English teaching, there are a variety of English approaches and methods widely used by the English teachers and each method is carefully selected to use based on the purposes and groups of students. According to Scrivener (2005), he proposed some well-known approaches and methods for English teaching including the Grammar-Translation Method (GTM), Audio-Lingual Method (ALM), Communicative Language Teaching (CLT) or Communicative Approach (CA), Total Physical Response (TPR), Community Language Learning (CLL), The Natural Approach, Task-Based Learning (TBL), The Silent Way, Person - Cantered Approaches, Lexical Approaches and Dogme. Furthermore, Lindsay and Knight (2006) mentioned that the Direct Method, GTM, ALM, CLT, and TBL are the main teaching methods which have influenced the ways of English teaching. Moreover, Scrivener (2009) suggested some well-known methods and approaches for English teaching, for example, GTM, ALM, TPR, and CLT. 
Interestingly, Intarapanich (2013) was investigated on teaching methods that used by English teachers in Vientiane Municipality, and the findings revealed that CLT, GTM, and TPR were the three major teaching methods found in EFL classes. Additionally, the researcher myself as a teacher was responsible for preparing English student teachers for their teaching practicum. Thus, some English teaching methods, for instance, GTM, ALM, TPR, and CLT were presented at the stage of preparation before teaching practicum. Subsequently, the study was attempted to investigate the English teaching methods used by pre-service teachers and to study about the impacts on learners' learning using those selected teaching methods.

\section{Methodology}

This session of the research was conducted through classroom observation and informal individual interviews with the guided questions to reveal the detailed information. The 20 participants were pre-service English teachers from the Faculty of Education, Suratthani Rajabhat University. They were selected by purposive sampling based on their school level for their teaching practicum and under supervision by the researcher as their supervisor.

\section{Data analysis}

The observation forms were designed to collect data about teacher's teaching and students' learning behaviors in actual classes. The quantitative data from the observation was analyzed and calculated to describe in frequency and percentages using SPSS version 21.0 (IBM Corp, 2012). The qualitative data was gathered from the semistructured interview, and all data were studied and grouped discourse analysis under the same theme. (Creswell: 2009)

\section{Results}

This study investigated the English teaching methods used by pre-service teachers for their teaching practicum and studied about the impacts on learners' learning of using those selected methods. The findings showed that GTM was used the most by pre-service teachers at 50\%, ALM was at 30\%, and TPR was at 20\%, respectively. However, there was no finding of using other methods. It can be seen that there were three main teaching methods used by pre-service teachers for their teaching practicum (See Figure 1).

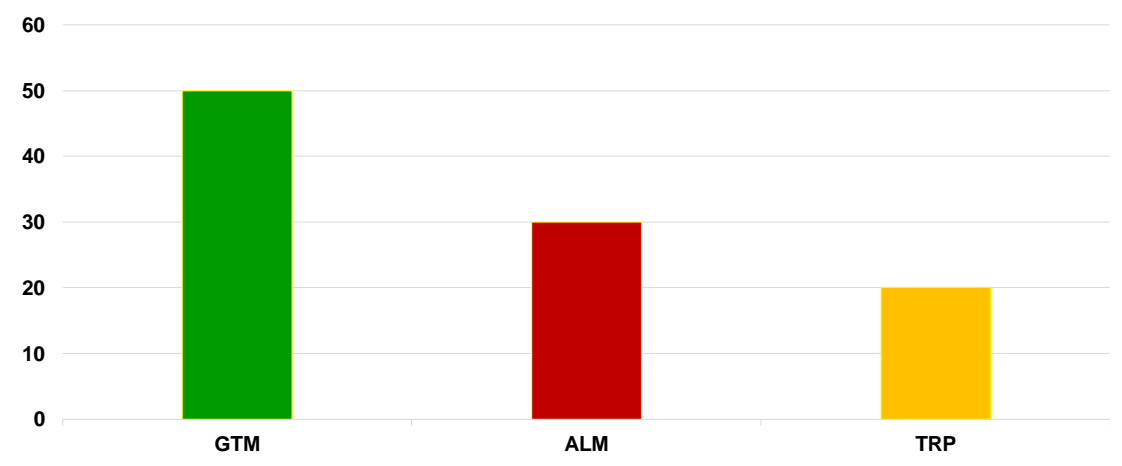

Figure 1 The teaching methods used by pre-service English teachers 
This study attempted to investigate what the teaching methods are used by pre-service teachers while practicing teaching at the primary schools and secondary schools. The above details had presented the overall teaching methods, which were used for both levels. However, the teaching methods used in primary schools and secondary schools were varied. The data in Figure 2 illustrated that in primary school level (for grade 1-6), the students were taught with different proportions of English teaching including GTM (10\%), TPR (40\%), and $\operatorname{ALM}(50 \%)$.

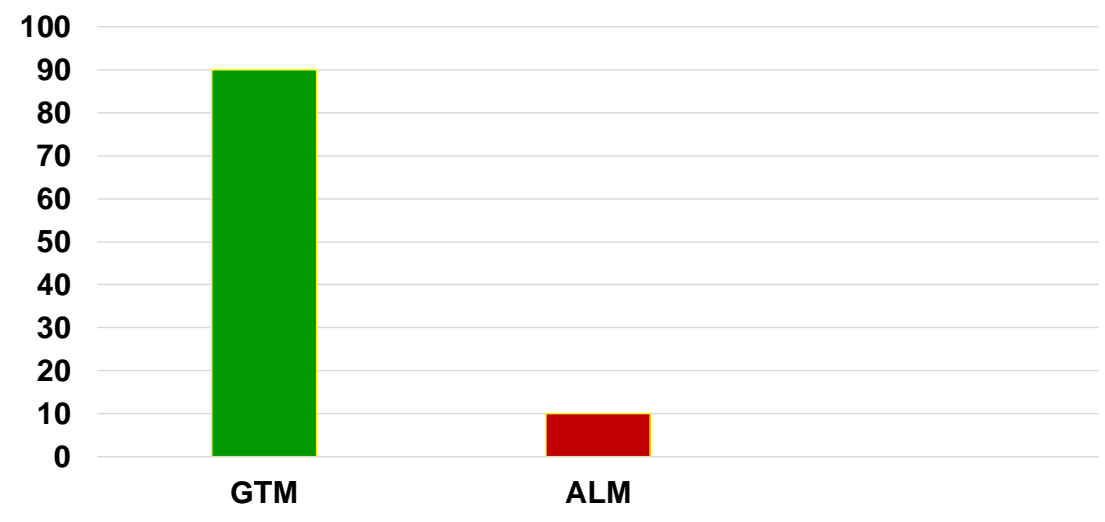

Figure 2 The teaching methods used by pre-service teachers in primary schools

The findings in Figure 3 presented the teaching methods used for secondary school level at grade 7 - 9 . It can be seen that GTM was used at the maximum of $90 \%$ while ALM was at only $10 \%$. From this result, it can be considered that GTM was the most popular method of teaching secondary school students.

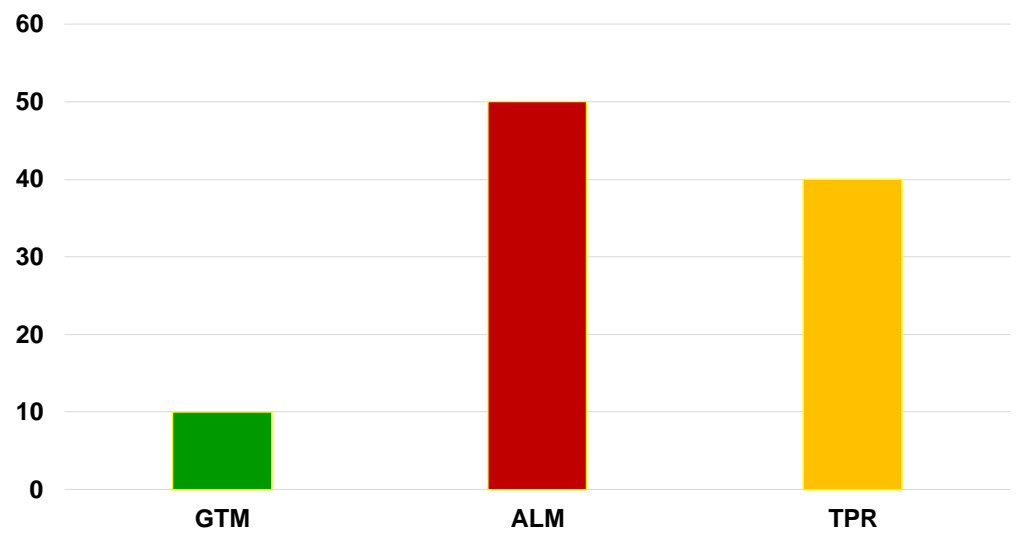

Figure 3 The teaching methods used in secondary schools

The figure below (Figure 4) showed that ALM, TPR, and GTM were the teaching methods which mostly used in primary level at 50\%, 40\%, and 10\%, respectively. While the methods which were used the most at the secondary level were, GTM which was presented at $90 \%$ and ALM was at only $10 \%$. Interestingly, the result revealed that the method which was used the most by pre-service teachers for their teaching practicum in primary school level is ALM. In contrast, it found that GTM was the most popular method used for teaching at the secondary schools. 


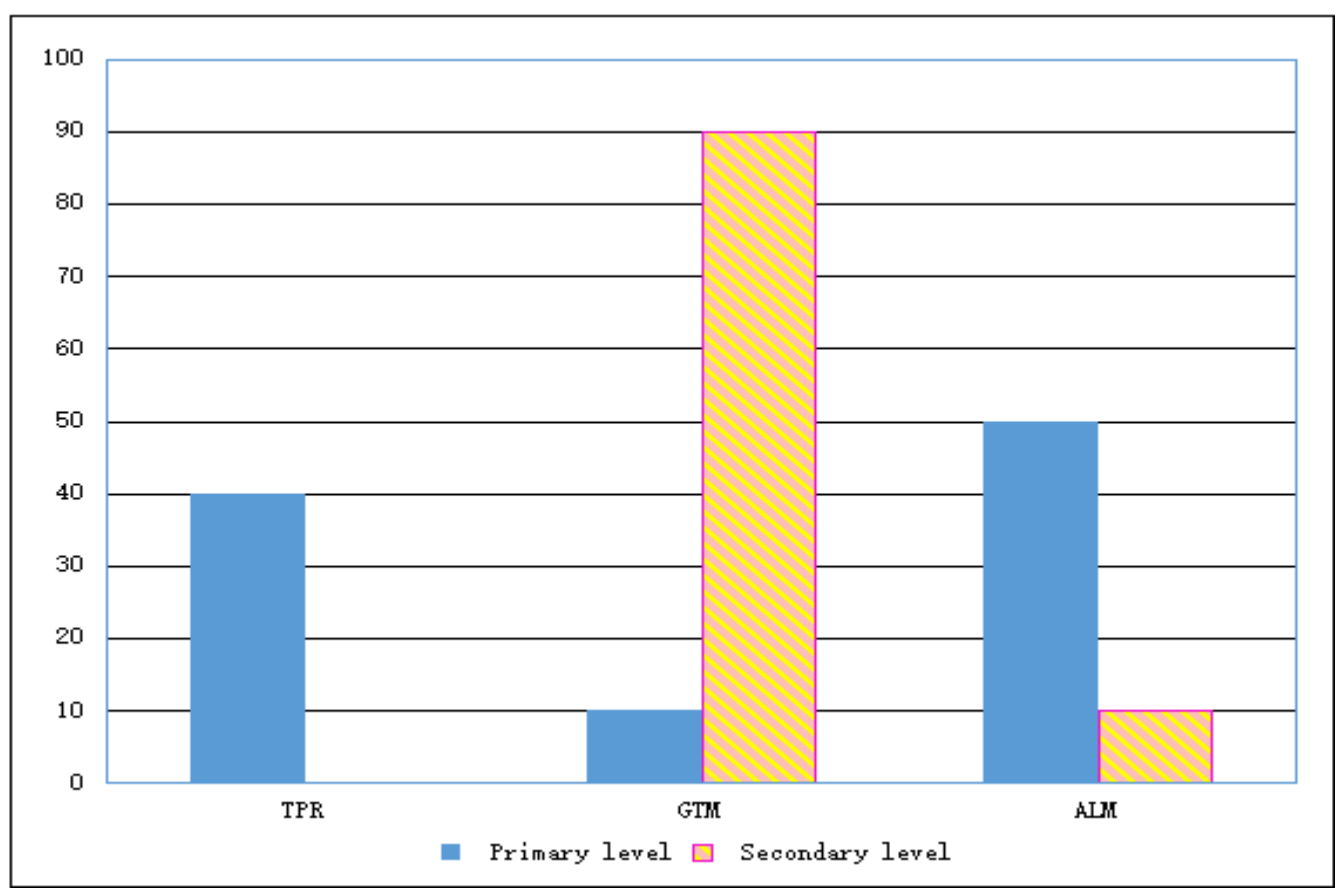

Figure 4 The comparison of methods used for both primary and secondary levels

This section will show the impacts on learners' learning of using the selected teaching methods. The data were analyzed and grouped under the same theme. It presents the analysis of the participants' thoughts and feelings on using the teaching methods for their classes. Four participants, who taught their learners by TPR, claimed that the learners are very young and at their age of $6-8$ years old they love to sing, play, and move around the classroom. So, TPR is the best method to be considered.

The data were collected from observation while teaching as well as the semi-structured interview was used to gain insight into learners' learning outcomes. The data were analyzed and group under the same theme. The following presents the impacts on learners' learning using the selected teaching method/approach.

The data showed that the learners who were taught by TPR enjoyed learning through physical movements entertaining by songs and actions. Their process of learning is simply by listening, watching, touching, acting and moving then imitating repeatedly. For ALM, learners are asked to repeat and drill to memorize the pattern and their mistakes particularly on pronunciation and intonation were concerned by the teacher. They were only required to speak out from what the dialogue was presented. While GTM, learners mainly learned about the structures and grammar rules through their mother tongue language but fewer opportunities provided using the target language.

\section{Discussion and Recommendation}

There are some relevant factors directly affected to choosing teaching methods which are the school requirement and teachers' perception. From the interview, the participants clearly stated that the school administrators proposed the idea of preparing secondary school students to learn English for the exam and they were expected to get a very high score. In addition, the participating in-service teachers claimed that using the first language through GTM is extremely good to help their students to understand and accomplish the objectives of the lesson easily because the language use is their own language. Accordingly, using the learners' mother tongue language enabled students to understand the lesson quickly. 
Furthermore, most Thai learners usually learn from the same processes which have been done for a long time as a conventional class. Then they might get familiar with traditional ways of teaching which are seen by the teachers that it is worth teaching to meet the background of their learning. It can be said that the teachers consider the teaching method/approach under their own belief and perception. It can be said that the direct impact on the learners' learning using this method is they completely became the passive learners.

It was found that some of the pre-service teachers who taught in primary school level particularly at the age of grade 1-3, TPR was mostly used. The students seemed to enjoy and participated better in the lesson learning through this method. The attention and participation were paid to physical movements for a smooth and good pace in an effective way. It can be said that the young students prefer learning through simple fun things, for instance, moving, playing, acting and singing.

According to the data gathered from the observation on grade $4-5$, the finding indicated that ALM was the method which mostly used. The researcher observed that the students participated well when they were asked to imitate the dialogue. The interesting point is that there were three pre-service teachers who viewed on teaching their classes by ALM became an effective solution to solve the problems of some students who have the low ability and low motivation in learning English. They were glad to see their students participate well in class through imitation and memorization. Although the students are rarely provided an opportunity to produce their own language, this at least encourages students to participate and get involved in the lesson interacting with their friends in class.

There are some suggestions to support pre-service teachers to develop their teaching performance to enhance the learners' learning which is about supervising and coaching. According to Nolan and Hoover (2008), they proposed the essential ideas on promoting individual teaching performance growth by working on the supervision cycle. Here are some ideas.

a) Mentoring; the supervisor needs to guide the pre-service teachers from the beginning stage which is creating a lesson plan. According to Scrivener (2005), he pointed out that a lesson plan can increase opportunities of a successful lesson helping teachers to cope with whatever happening during class. So it can be said that a lesson plan can be seen as an important tool in preparing for an effective class. These stages should be continuously done then it will be truly able to facilitate the professional growth of teaching performance.

b) Teaching training and teacher development; pre-service teachers may lack the ability to implement teaching techniques, for instance, communicative activities. It seems likely to be a limitation of selecting the teaching methods/approaches for their class. English class is a foreign language class in which learners are supposed to learn in interesting ways. According to Gentner (2014), he indicated about language instructions that Thai teachers prefer reading and writing exercises, but they rarely presented communicative tasks which could make the class fun. As well as, Beltman,. Glass,. Dinham,. Chalk,. \& Nguyen (2015) stated that it is time-consuming to develop pre-service teachers to be more professional in their teaching depending on various factors including teaching experience and preparation. Therefore, the pre-service teachers need to be trained and prepared well about teaching techniques and strategies to promote students engagement in learning. This may extremely be useful to maintain the positive impacts on the learners' learning.

\section{Conclusion}

The study has attempted to investigate what English teaching methods were used by pre-service teachers for their teaching practicum and to find out what the impacts on learners' learning using those selected methods. The findings highlighted that there were only three methods which were used by pre-service teachers. The impacts on learners' learning at primary school, learners learned language actively in physical through movements and learned to speak the target language through repetition with less focus on real communication. 
While secondary school learners learned about grammar rules and structures to get a high score on the exam. There are some suggestions presented to develop teaching performance to promote the positive impacts on learners' learning. The mentoring and coaching should be implemented to foster pre-service teachers to perform better in their teaching. It is necessary for the supervisor to give advice at the beginning of their teaching practice and give feedback on their actions in class as a reflection. This is suggested to be done continuously.

\section{Acknowledgements}

This research would not have been completed without the help from my supervisors. I am deeply grateful for their valuable suggestions and advice. Additionally, I would like to thank all participants for their cooperation and my colleagues for their encouragement and special support throughout the whole process of completing this study.

\section{References}

Beltman,. S, Glass, C., Dinham, J., Chalk, B., \& Nguyen,. B. (2015). Drawing identity: Beginning pre-service teachers' professional identities. Issues in Educational Research, 25(3),

Creswell, J. (2009). Research Design ( $3^{\text {rd }}$ ed.). Thousand Oaks, California: SAGE Publications, Inc.

Gentner, M. (2014). Teaching English to Thai learners. Bangkok University Press.

Intarapanich, C. (2013). Teaching Methods, Approaches and Strategies Found in EFL classrooms: A Case Study in Lao PDR, Procedia - Social and Behavioral Sciences, Vol. 88, 10 October 2013, pp. $306-311$.

Nolan, J. F., \& Hoover, L. A. (2007). Teacher supervision and evaluation: Theory into practice (2 ${ }^{\text {nd }}$ ed.). NJ: John Wiley \& Sons.

Lindsay, C., \& Knight, P. (2006). Learning and Teaching English. Oxford University Press.

Scrivener, J. (2009). Learning Teaching. (2 $2^{\text {nd }}$ ed.). Macmillan.

Fredrickson, T. (2016). More English for Prathom students. Bangkok Post. Retrieved June 26, 2016, from http://www.bangkokpost.com/learning/easy/1003037/more-english-for-prathom-students 